\title{
Homework as a metacognitive tool in an undergraduate physics course
}

\author{
Ana Rita Mota, ${ }^{1,2, *}$ Nilüfer Didiş Körhasan, ${ }^{1,3}$ Kelly Miller, ${ }^{1}$ and Eric Mazur ${ }^{1}$ \\ ${ }^{1}$ School of Engineering and Applied Sciences, Harvard University, 02138, Cambridge, Massachusetts, USA \\ ${ }^{2}$ CF/UM/UP, Departamento de Física e Astronomia, FCUP, Portugal \\ ${ }^{3}$ Department of Mathematics and Science Education, Zonguldak Bülent Ecevit University, \\ 67300, Zonguldak, Turkey
}

(Received 1 October 2018; published 31 May 2019)

\begin{abstract}
A considerable body of research shows that individuals who demonstrate a wide variety of metacognitive skills perform better on scientific problem solving. We developed a way of implementing homework in an undergraduate physics course to promote metacognitive skills. This novel homework design includes both an individual and a team phase and was implemented in a team-based learning environment. We developed a coding table to conduct both qualitative and quantitative analyses of students' expressions of metacognitive thinking. Results indicate that students' expressions of metacognitive thinking improved during the term. Data also show that team discussion helps improve metacognitive skills.
\end{abstract}

DOI: 10.1103/PhysRevPhysEducRes.15.010136

\section{INTRODUCTION}

Metacognition refers to awareness of one's own knowledge and the ability to understand, control, and influence one's cognitive processes. There is increasing interest in metacognition in science education, as it is widely accepted that developing metacognitive skills is an integral part of the learning process [1-7]. A considerable number of studies show that students who receive metacognitive instructions and training perform better on self-regulated learning activities and demonstrate higher levels of motivation after instruction [5]. Such learners construct knowledge using cognitive strategies while planning, monitoring, and evaluating their thinking. It is through this thinking about thinking - this use of metacognitive strategies - that learning is maximized. As students become more skilled at using metacognitive strategies, they gain confidence and become more independent as learners. Individuals with well-developed metacognitive skills use a repertoire of strategies to think through a problem or approach a task, and they can transfer these strategies to new settings. These individuals also reflect on their own thinking processes, learn from mistakes, and make decisions about a course of action to resolve the problem or successfully perform the task $[1,7]$.

Several studies demonstrate that students' metacognitive abilities improve if students are explicitly taught to develop them $[5,6,8,9]$. One way to enhance metacognitive abilities

\footnotetext{
*ana.mota@fc.up.pt
}

Published by the American Physical Society under the terms of the Creative Commons Attribution 4.0 International license. Further distribution of this work must maintain attribution to the author(s) and the published article's title, journal citation, and DOI. is to create a learning environment where students are required to explain and discuss their thought processes $[1,5,10]$. In other words, instructors need to prompt learners to think about what they are doing as they complete the tasks. Examples of metacognitive activities include planning how to approach a learning task, involving appropriate skills and strategies to solve a problem, monitoring comprehension of the task, and evaluating progress toward the completion of a task.

Metacognition is critical in contributing to students' learning of physics [11], specifically when it comes to problem solving [12-14]. Metacognitive skills allow students to know how to coordinate, when to use, and how to monitor problem-solving skills in academic tasks. Research shows that individuals who demonstrate a wide variety of metacognitive skills during physics problem solving perform better on problem solving in general [12-15].

In this paper we first briefly review metacognition and its importance in the development of problem-solving skills. This theoretical backdrop is followed by a description and discussion of our research methodology: a problemsolving model designed to develop metacognitive skills in a team-based learning environment. We describe the coding scheme used to analyze students' expressions of metacognitive thinking during a set of five problem sets ( $p$ sets), and we answer the following research questions:

(1) Do students' metacognitive skills improve over the course of the semester?

(2) What is the relationship between students' rating of their own understanding and their performance in the course?

Based on the answers of these research questions, we discuss the contribution of this $p$-set design to the development of metacognition skills in problem solving. 
Despite improvements over the last few decades in the metacognition field, $[15,16]$ there is still insufficient research on metacognition among learners at all levels of teaching. Instructors' knowledge and professional development regarding metacognitive skills is also scanty. We explore the implications of these research gaps and suggest future research directions.

\section{METACOGNITION IN PROBLEM SOLVING}

After Flavell introduced the concept of metacognition [17] a large body of research on metacognition has developed over the last thirty years. The literature tends to distinguish two components of metacognition: metacognitive knowledge, also called knowledge of cognition, and metacognitive regulation (or regulation of cognition) [17-19]. Knowledge of cognition refers to what individuals know about themselves as cognitive processors, about different approaches that can be used for learning and problem solving, and about the demands of a particular learning task. This component includes three metacognitive subcomponents: declarative, procedural, and conditional knowledge.

- Declarative knowledge refers to knowledge about one's skills, intellectual resources, abilities as a learner, awareness of one's strengths and weaknesses in learning and processing information.

- Procedural knowledge refers to knowledge about how to implement learning procedures.

- Conditional knowledge refers to knowledge about when and why to use specific learning procedures $[17,18]$.

Regulation of cognition refers to adjustments or actions individuals make to control or regulate their learning. This regulation of cognition includes five different subcomponents: planning, monitoring, evaluation, information management strategies, and debugging strategies [18].

- Planning refers to goal setting and allocating resources prior to learning.

- Monitoring refers to assessing one's learning or strategy.

- Evaluation refers to analyzing the performance and effectiveness of a strategy after a learning episode.

- Information management strategies are related to the skills and strategy sequences used to process information more efficiently (e.g., organizing, elaborating, summarizing, using free-body diagrams).

- Debugging strategies are related to strategies used to correct learning comprehension and performance errors.

Teaching students to be effective problem solvers is considered a primary goal of physics instruction. Many studies $[2,13,15,20]$ have already examined the roles of cognition, metacognition, and motivation in student problem-solving efficacy. It has been found that possessing domain-specific skills in itself is not sufficient to support problem-solving transfer [21], and cognition, metacognition, and motivation are important ingredients required for successful problem solving.

Metacognitive strategy training $[5,22]$ shows that knowledge of cognitive skills is not enough for successful performance on complex academic tasks such as problem solving. Students benefit from training that is sensitive to the metacognitive demands of the task, that is, from learning when and how to apply domain-specific learning strategies. The term "conditional knowledge" can be used to describe this aspect of metacognition. Mayer provides an interesting example [20]: Imagine that a student must solve the following problem: Gas at ARCO costs $\$ 1.18$ per gallon. This is 5 cents less per gallon than gas at Chevron. If you want to buy 5 gallons of gas, how much will you pay at Chevron? It is conceivable that a student who knows how to add, subtract, divide, and multiply still would not arrive at a correct answer. The student subtracts $\$ 0.05$ from $\$ 1.18$, yielding $\$ 1.13$; then one multiplies $\$ 1.13$ by 5 , producing a final answer of $\$ 5.65$. Why did the student fail? According to problem-solving experts [23-25], solving a problem requires students to represent the problem, devise a solution plan before executing it, monitor their understanding as they are executing the plan (using "fixup" strategies when meaning breaks down), and finally evaluate their solution after completing the task.

Lewis showed [22] that when students are taught how to represent story problems using a number-line diagram, students' problem-solving performance improved dramatically, and they were able to transfer what they had learned to new types of problems. This implies that in addition to mastering the requisite arithmetic and algebraic skills, students need to learn when and how to apply domainspecific learning strategies. The best way to help students regulate their problem-solving strategies is cognitive modeling of problem solving in context; in other words, having efficient problem solvers describe their thinking process as they solve a problem [26,27].

Moreover, students who are self-regulated learners believe that taking on challenging tasks and exerting effort provide an opportunity to practice learning and develop a deep understanding of subject matter, which, in turn, will result in academic success. These characteristics may explain why self-regulated learners typically exhibit a high sense of self-efficacy [28]. In the educational psychology literature, researchers have linked these characteristics to success in and beyond school.

In conclusion, problem solving is a complex cognitive process and there is no overall "problem-solving" ability construct; instead there are many subskills that affect a person's ability to solve complex problems in many different contexts [29]. The existence of so many distinct important subskills explains why it has been so hard to teach and assess problem solving as a single distinct skill, and sheds light on the gap between effective problem 
solving and conceptual understanding [30-34]. Still, studies have shown that students' problem-solving ability and metacognitive skills improve as a result of collaborative work [35-38]. This finding shows that even though studying how people engage in problem solving is a very diverse and complex endeavor [39], collaborative work provides an opportunity for instructors to help students develop metacognitive skills.

\section{PROBLEM-SET REFLECTION}

\section{A. Team and project-based learning environment}

We introduced a novel approach to homework in an introductory physics course for engineering and premedical students, which is different from the approach commonly used in introductory science courses. This "problem-set ( $p$-set) reflection" explicitly involves metacognitive skills. The overall course is taught in a team and project-based learning environment and covers a subject area equivalent to a standard introductory physics course. The approach of the course is designed to promote self-directed learning of physics, explore physics in the context of real-world applications, improve collaborative and communication skills in team-driven activities, and develop research skills by working on projects.

The course blends six best practices in a flipped classroom and Peer Instruction [40] framework. The class meets twice a week for three hours. There are no other regularly scheduled class meeting times - no standard laboratory or no discussion sections.

Before coming to class, students are required to annotate an electronic version of the textbook using a social document annotation system called Perusall [41]. The instructors use these annotations to adjust the activities in class, according to a flipped classroom methodology.

In class, students work on a series of guided, scaffolded activities that help them develop a solid understanding of the physics principles required to successfully complete the projects. The in-class activities vary day by day and most of the activities are not assessed, leaving ample room for students to make mistakes without a grade being at stake. Consequently, students see the activities as learning opportunities and learn to deal with productive failures that go hand in hand with creativity. The activities are scaffolded so that those at the beginning of each topical unit focus on building conceptual understanding and those towards the end of each unit are designed to help students assess their own learning. Sequentially, these six activities are

(I) Learning catalytics: Peer Instruction implemented using an online platform.

(II) Tutorials: worksheets that probe and address common misconceptions [42].

(III) Estimation activities: a team competition aimed at developing estimation and order-of-magnitude skills.
(IV) Experimental design activities: activities designed to help students develop experimental skills required by the projects.

(V) Problem-set reflection (see below).

(VI) Readiness assurance activity (RAA): formative assessment in the form of a two-stage, collaborative exam.

Toward the end of each month-long project, an increasing amount of time in class is allocated for the students to work on their projects. During that time students may be working in the classroom or in the teaching labs, where a machine shop is available. The month-long projects are designed to engage the students and help them take ownership of their learning. The team-based approach provides a social responsibility for the learning; students need to keep up with the work to avoid letting their team down and are responsible for the performance of the entire team. Finally, flipping the classroom helps move the information transfer out of the classroom, so that students can take part in cognitively more engaging tasks during class time.

\section{B. $p$-set reflection: Individual and team phase}

The problem-set reflection includes both an individual and a team phase. Students receive the problem-set assignment (typically a set of 5 problems) a week before they are due, and they work individually on solving the problems outside of class. They are instructed to work alone and without the help of peers and give all five problems their best effort using a highly structured problem-solving strategy consisting of the following four steps:

(I) Getting started: State the important information and summarize the problem. If possible, include a diagram. Note any assumptions you are making.

(II) Devise plan: Devise a plan of attack before diving into the solution. Break down the problem into smaller, manageable segments. Identify which physical relationships you can apply.

(III) Execute plan: Carry out your plan, explaining each step. The argument should be easy to follow. Articulate your thought process at each step (including roadblocks). Any variables should be clearly defined, and your diagrams should be labeled.

(IV) Evaluate solution: Check each solution for reasonableness. There are many ways to justify your reasoning: check the symmetry of the solution, evaluate limiting or special cases, relate the solution to situations with known solutions, check units, use dimensional analysis, and/or check the order of magnitude of an answer.

The four-step procedure can be considered as a heuristic organization of the way of thinking from expert problem solvers. It forces students to break down each problem and follow a specific problem-solving approach, and helps students keep their focus and attention, derive meaning, and make adjustments if something goes wrong $[10,12,13]$. 
In this first (individual) phase students have to use blue or black ink. The work completed during this phase is evaluated on effort, not on correctness. Students can consult the textbook, online resources, and teaching staff. However, as stated before, they may not collaborate with their peers. As only effort is evaluated, students must attempt every problem, even those that they are not sure how to approach. If they reach the evaluate stage and find that their answer does not seem reasonable, they are encouraged to describe their thought process, so they are prepared for a discussion with their team in class. If they get stuck in the execute plan stage and there is no solution to evaluate, they should still attempt to use estimation skills to get a feeling for what would constitute a reasonable answer to the problem (such as a reasonable order of magnitude).

The second (team) phase takes place in class. During this phase, they may only use a red pen. Students compare their solutions with those of their teammates, reflect on their work, resolve conceptual difficulties, and identify areas that need to be reviewed. This reflection phase has 3 different phases:

(I) In the first 45 min, students discuss their solutions with their team. During this discussion, students correct and annotate their work with a red pen.

(II) In the second $45 \mathrm{~min}$, the team must compare their solutions to the "official" solutions provided by the teaching staff.

(III) At the end of the hour and half long period, students complete a self-evaluation or reflection form (Appendix A).

It is the team's responsibility to ensure that all team members hand in complete and completely marked up solutions together with a completed reflection sheet, as each team's submitted work will result in a shared team score. This means that if a single team member does not put in adequate effort before the team or reflect phase, they will lower not only their own score, but also that of their team members. Likewise, it is important to ensure that everyone on the team marks their work up correctly during the team or reflect phase.

\section{Scoring}

This $p$-set model was designed to help students develop problem-solving skills and deemphasize students' urge to just provide the right answer. The overall problem set is evaluated on two domains: effort and reflection. Each $p$ set is evaluated on the effort students put into solving each problem by applying the four-step problem-solving procedure, before coming to class. The reflection score is based on clearly identifying and explaining any conceptual or mechanical errors made (or encountered) while working on the problem alone. Both reflection and effort scores are on the 0-3 scale as presented in Appendix B. It is possible for students to obtain a maximum score on the problem set, as long as they (a) demonstrate an effort in applying the four-step problem-solving technique to all the problems and (b) identify and explain their mistakes in the reflection.

On the self-evaluation and reflection form, students are required to reflect on the mistakes they made on the problem set and comment on how they could improve their understanding of the concepts covered in the problem set. As part of this reflection, students rated their level of understanding of the material on the problem set on a three-category scale: green, yellow, or red (Appendix A, question 4). Green means that the student feels they are conceptually on track, yellow means the student feels there are some conceptual deficiencies that require attention, red means that the student feels there are important conceptual barriers that need to be addressed before further progress can be made. Students are evaluated on the effort they put into the application of the four problem-solving steps and the accuracy of their self-evaluation rather than the correctness of their answers.

Finally, these two scores are combined into an individual score, and all team members' individual scores are averaged to generate a team score.

\section{METHODOLOGY}

\section{A. Data collection}

Sixty-five students from an undergraduate physics course at Harvard University participated in this study. During the semester, each student completed five problem sets. We analyzed the reflection forms for each $p$ set; students who did not complete all five $p$ sets were not included in the study. Content analysis was conducted on $325 p$ sets ( 65 students $\times 5 p$ sets).

In each $p$ set we identified and classified students' expressions of metacognitive thinking into their metacognitive subcomponents. We focused our study on students' responses to the following questions from the reflection form (Appendix A).

- Question 3: Describe what you learned from working on this problem set before coming to class and reviewing it in class. (Do you think you would be able to take the concepts you explored in this problem set and transfer those concepts in a whole new context?) For example, would you be able to solve a problem involving the same physics concepts, but of a form you have never seen before?).

- Question 4: Overall rating of your understanding of the material (check one)

GREEN: Good general understanding

YELLOW: Some barriers in understanding

RED: Substantial barriers in understanding

\section{B. Data analysis}

Development of coding table, validity, and reliability of coding.-We followed the taxonomy developed by Schraw 
TABLE I. Final version of the codes and sample coding for each metacognitive component.

\begin{tabular}{|c|c|c|}
\hline Metacognition component & (Sub)metacognitive component & Sample coding from students' explanations \\
\hline \multirow[t]{3}{*}{$\begin{array}{l}\text { Knowledge of } \\
\text { cognition }(\mathrm{KC})\end{array}$} & Declarative knowledge (DK) & $\begin{array}{l}\text { I feel that I have a good general understanding of this material. } \\
\text { I felt very confident in solving the problems in this } p \text { set. }\end{array}$ \\
\hline & Procedural knowledge (PK) & $\begin{array}{l}\text { In problem } 1 \text {, I was able to practice my estimation abilities. } \\
\text { I am now clear about the derivation. } \\
\text { I have definitely learned how to handle these problems better. }\end{array}$ \\
\hline & Conditional knowledge (CK) & $\begin{array}{l}\text { I could also apply and manipulate formulas to given scenario. } \\
\text { I can apply these ideas in a new context. }\end{array}$ \\
\hline \multirow[t]{6}{*}{$\begin{array}{l}\text { Regulation of } \\
\text { cognition (RC) }\end{array}$} & Planning $(\mathrm{P})$ & $\begin{array}{l}\text { I did not get struck at any point, but the first problem had me } \\
\text { thinking for a while before I got started. }\end{array}$ \\
\hline & Monitoring (M) & $\begin{array}{l}\text { I learned I need to be more thorough in "sanity checks" to see } \\
\text { if I am in the right area. } \\
\text { I checked my answers. }\end{array}$ \\
\hline & Evaluation $(\mathrm{E})$ & $\begin{array}{l}\text { I made a mistake with numbers. } \\
\text { My main barrier was incorrectly using one of the formulas. } \\
\text { I forgot to include a time interval in my final calculation. }\end{array}$ \\
\hline & $\begin{array}{l}\text { Information management } \\
\text { strategies (IMS) }\end{array}$ & $\begin{array}{l}\text { The } p \text { set taught me the importance of drawing models for } \\
\text { kinematics problems because they help simplify things in } \\
\text { complex multipart problems. } \\
\text { I learned how to split up a problem into simpler components, } \\
\text { so it becomes more manageable. }\end{array}$ \\
\hline & Debugging strategies (DS) & $\begin{array}{l}\text { I mostly referenced to the textbook and google to help some } \\
\text { problems I struggled with. }\end{array}$ \\
\hline & & I stop and reread when I got confused. \\
\hline
\end{tabular}

[18] and Taasoobshirazi [16,43] to develop a coding table. In 2013, Taasoobshirazi and Farley [43] developed a helpful tool to measure physics students' metacognition for problem solving - the Physics Metacognition Inventory (PMI). An exploratory analysis revealed six components of students' metacognition when solving physics problems (knowledge of cognition, planning, monitoring, evaluation, debugging, and information management). In spite of being reliable and valid, these researchers revised them to improve its construct validity, through a confirmatory factor analysis and a Rasch analysis [16]. In the final (revised) PMI, the researchers presented eight categories ( 3 for metacognitive knowledge and 5 for regulation of cognition) to examine metacognitive issues in physics problem solving.

We determined coding categories using the PMI, wrote detailed descriptions for each category and coded sample items from $p$ sets. To provide internal validity, we asked two experts studying metacognition in science education to examine the coding in terms of (i) the metacognition dimensions, (ii) the descriptions of the codes, and (iii) the appropriateness of sample coding. The experts gave feedback about the (i) mutual exclusiveness of the codes (each code must not overlap), (ii) appropriateness and description of the codes (codes vs code descriptions), and (iii) coding (code descriptions vs sample coding) to provide internal validity. After getting feedback about codes and coding, we discussed the comments and established the final coding. After validating the codes, we determined the appropriate unit of analysis for coding. In order to investigate the students' reflective statements, we considered each meaningful phrase or sentence (separated by punctuation marks or connectors) as a coding unit and coded that unit with a specific code corresponding to one of the metacognitive subdomains. Table I presents the final version of the codes and sample coding from the data.

To determine the reliability of the coded data and quantify the agreement between the different coders, we analyzed the intercoder reliability [44]. According to Miles and Huberman [45], agreements in coding 5-10 pages of text never exceeds $70 \%$. Two of the authors started coding the data together by discussing students' responses to question 3 on $3 p$ sets ( 3 students $\times 5$ pages) and categorizing them as a type of metacognitive subcomponent. After obtaining clear discriminations for each subcomponent, the two raters independently coded and analyzed $5 p$ sets (5 students $\times 5$ pages). Then, the raters compared their coding and discussed the questions for which there was disagreement (about 40\%) and resolved all disagreements. Afterwards, the researchers continued to randomly select $5 p$ sets and code students' responses until they reached adequate reliability $(>0.70)$ in selected $p$ sets at the end of the third step of intercoder reliability examination.

After ensuring the validity of the coding with expert feedback and the reliability of the inter-rater coding, we analyzed 1208 student responses in $325 p$ sets from 65 students. For example, a phrase referring to the ability of making estimates would be scored as procedural knowledge; 
the phrase would be coded as PK and one point added to this code to count the frequency of this metacognitive subdomain. After the qualitative coding of all $p$ sets, we carried out a statistical analysis to determine the frequency of each code for each student and each $p$ set. We examined the frequency of students' expressions of metacognitive thinking over the semester for females versus males and the improvement of metacognitive thinking over the course of the semester.

By considering students' self-evaluations in the 4th question on the reflection form, we calculated the difference between their self-rating of their overall understanding (ORU) and their actual scores on the readiness assurance activity (RAA). The ORU is an interval variable (0, red; 1, yellow; 2, green) and the RAA score is a continuous variable (between 0 and 1 where 1 represents the maximum score). Comparing students' self-rated scores to their actual exam scores provides us with a measure of how well they are judging their own understanding. Looking at how the gap between self-rating and actual performance changes over the semester provides us with a measure of how students' metacognitive skills develop.

\section{RESULTS}

Overall evaluation of students' $p$-set reflections show that the students greatly value the team discussions in improving their skills. This points to the importance of the team phase in this $p$-set model design. Some representative comments from students' reflections are reproduced below.

"Both doing the problem set on my own and talking about it with my teammates were useful activities. (...) Going on the problem set with my teammates helped me see where my logical thinking went astray. It is amazing how much clearer things become by discussing them. It must have to do with the $\mathrm{Q}+\mathrm{A}$ aspect of discussion: Why did you do that?"

$$
* * *
$$

"I learned that it is very helpful to keep my notation clear and explicitly state my givens. Not only does it make explaining my solutions to classmates easier, but it makes my process more streamlined when I'm working through solutions or finding where I went wrong specifically."

$$
* * *
$$

"I learned different ways of approaching the problems because my teammates used different methods."

"I have a solid understanding of time-dependent wave equations after reviewing with my team”

"I definitely think the concepts I learned on this p set are transferable, especially because after checking things

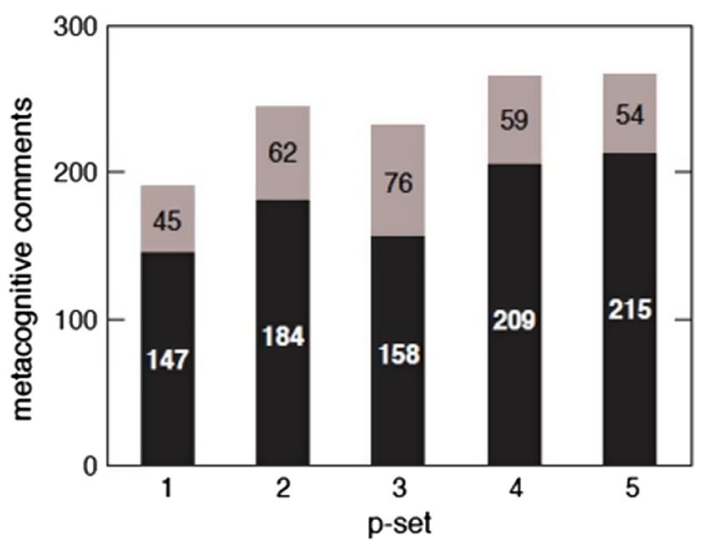

FIG. 1. Number of metacognition comments over time. The number of comments in the knowledge of the cognition (black) category increases over the semester. There is no significant increase in the regulation of cognition category (gray).

and discussing it in a group setting, I really feel like I have a good handle on the concepts now."
***

"My discussion with fellow teammates and the opportunity to share with them some of my approaches to some problems deepened my own understanding of the concepts."

"I learned to discuss physics problems (it's hard to talk and make sense...)"

We found a significant number of comments similar to these. Students often comment on the importance of the team in the construction of their own knowledge: in their words, the group work encourages deeper learning, increases their responsibility, and expands critical thinking, communication skills, self-learning, and respect for others.

Figure 1 presents the distribution of the number of metacognitive comments, by each metacognition component, over time. Overall, the number of metacognitive comments increases over time, however, when we look at the number of comments in each category, we see that only the number of comments in the knowledge of cognition category has increased significantly, whereas in the other category there is no significant increase.

Table II complements Fig. 1 and shows the distribution of each metacognitive subcomponent appearing in the students' five $p$-set reflections during the semester. The majority of the expressions of metacognitive thinking belong to the knowledge of cognition category, most of the comments belonging to declarative knowledge. We confirm that the number of comments in the regulation of cognition dimension does not show a significant increase, except in the ability to evaluate a certain task, which improved over time. 
TABLE II. Percentage of each metacognitive subcomponent over five problem sets. The number of knowledge of cognition comments are more expressive than the regulation of cognition ones. The number of different components changed randomly over the semester, with always a highest number of declarative knowledge comments. On the other hand, the number of comments only increase significantly in the knowledge of cognition domain. Abbreviations for knowledge of cognition and regulation of cognition subcomponents are given in Table I.

\begin{tabular}{|c|c|c|c|c|c|c|c|c|}
\hline \multirow[t]{2}{*}{$\begin{array}{l}p \\
\text { set }\end{array}$} & \multicolumn{3}{|c|}{$\begin{array}{l}\text { Knowledge of cognition } \\
\text { Number of comments }(\%)\end{array}$} & \multicolumn{5}{|c|}{$\begin{array}{l}\text { Regulation of cognition } \\
\text { Number of comments }(\%)\end{array}$} \\
\hline & DK & PK & CK & $\mathrm{P}$ & $\mathrm{M}$ & $\mathrm{E}$ & IMS & DS \\
\hline 1 & 31.3 & 18.2 & 27.1 & 2.1 & 2.1 & 6.3 & 12.5 & 0.5 \\
\hline 2 & 32.2 & 21.2 & 21.6 & 2.0 & 4.5 & 8.6 & 7.3 & 2.4 \\
\hline 3 & 30.3 & 11.5 & 25.6 & 1.3 & 3.0 & 10.3 & 16.2 & 1.7 \\
\hline 4 & 45.1 & 15.7 & 17.2 & 0.7 & 2.6 & 10.1 & 5.6 & 3.0 \\
\hline 5 & 32.3 & 26.8 & 20.8 & 1.9 & 1.5 & 8.9 & 4.1 & 3.7 \\
\hline
\end{tabular}

We carried out a mixed between-within subjects ANOVA to compare the metacognitive comments of students during the semester. The mean and standard deviations of the number of metacognitive comments per student (considering all eight metacognitive subcomponents) for each successive $p$ set is shown in Fig. 2. The data clearly show a trend, the number of metacognitive comments increases significantly over the course of the semester $[p=0.000$, Wilks' lambda $=0.596, F(4,60)=10.181, p<0.05$, multivariate eta squared $=0.404]$.

A post hoc comparison using the Bonferroni test indicates that the mean $(M)$ number of metacognitive comments (including knowledge of cognition and regulation of cognition) for problem set $1[M=2.9$, standard

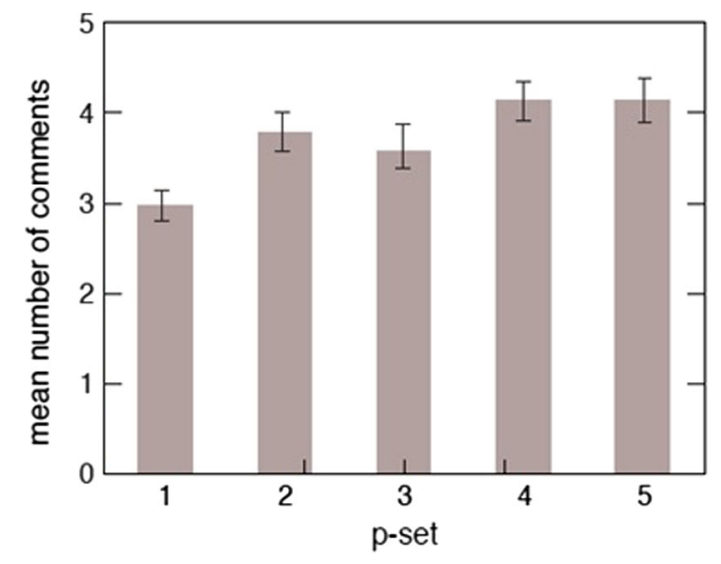

FIG. 2. Mean and error bars of the number of metacognitive comments written by students during the semester. The data show a statistically significant improvement in the students' metacognitive skills.

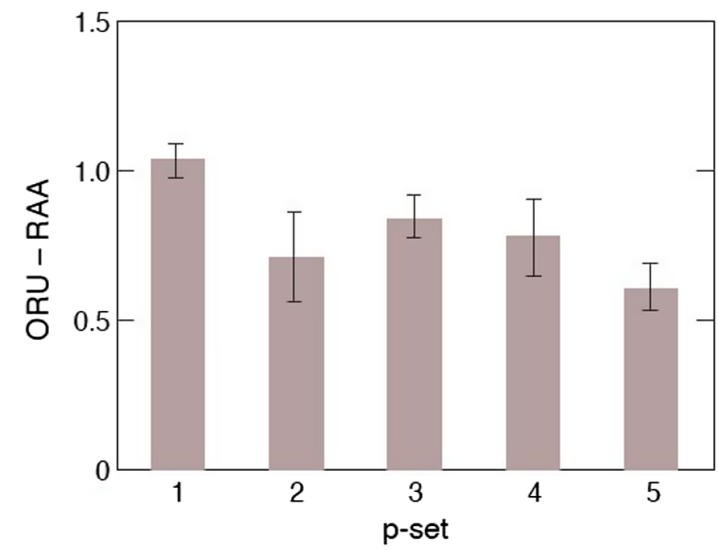

FIG. 3. These data show a statistically significant decrease in the difference between students' self-rating of their overall understanding and their actual scores on the readiness assessment activities, which suggest that students are getting better at selfevaluation as the semester progresses. These findings indicate a high probability that students' metacognitive skills have improved during the semester. The error bars represent the $95 \%$ confidence interval.

deviation $(\mathrm{SD})=1.2]$ is significantly different from that for problem set $4(M=4.1, \mathrm{SD}=1.7, p=0.001)$ and problem set $5(M=4.1, \mathrm{SD}=1.8, p=0.001)$. The mean in problem set $2(M=3.8, \mathrm{SD}=1.7)$ and problem set 3 $(M=3.6, \mathrm{SD}=1.9)$ is also higher than problem set 1 but not significantly. We also find that there is no significant difference in the number of metacognitive comments for females and males $[F(1,63)=1.3$, $p=0.25]$. In addition, the data reveal no statistically significant interaction effect between gender and change in the number of metacognitive comments over time $[F(4,60)=0.6, p=0.6]$.

Figure 3 shows how the difference between students' self-rating of their overall understanding (ORU) and RAA scores evolves over the course of the semester.

The observed decrease in the difference indicates that students improve in their ability to accurately evaluate their own level of conceptual understanding of the course material over the course of the semester with a significant difference between $p$ set 1 and $p$ set $5(p=0.039)$. In other words, students' metacognitive skills improve over the course of the semester.

We do find, however, that females have less confidence overall in their own understanding than males. Curiously, female students consistently self-rate their own level of understanding of the material below that of male students even though there is no gender difference in actual performance. As seen in Fig. 4, the performance of males (29 students) and females (36 students) is not statistically different (measured by the RAAs) and yet female students rate their level of understanding as significantly lower than male students $(p<0.05)$. 


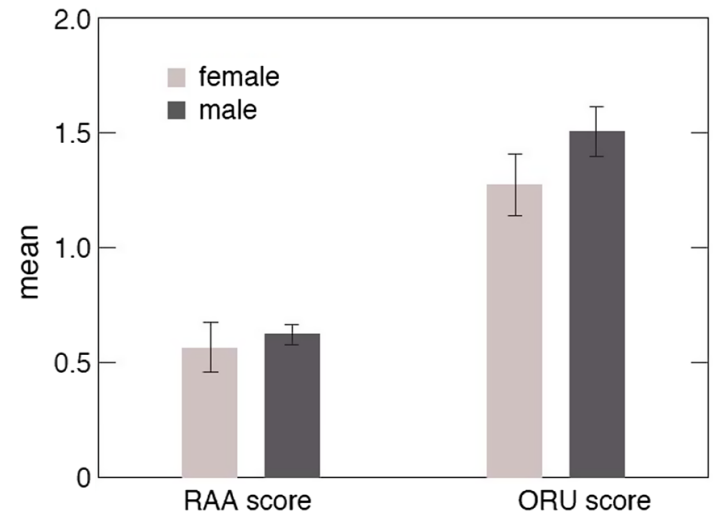

FIG. 4. Mean of students' self-rating of their overall understanding (ORU) and readiness assurance activity scores for males and females. Error bars show the standard error of the mean. Even though there is no statistically significant gender difference in RAA performance, females have statistically significantly less confidence in their own level of understanding.

\section{DISCUSSION}

Problem solving is a key component of most physics' courses [46-48], but isolating specific factors for improving performance in this task has proven challenging. Nevertheless, previous research has shown that individuals who demonstrate a wide variety of metacognitive skills during physics problem solving perform better [11-13,15]. In this paper, the problem-set reflection is designed to help students develop self-assessment, metacognition, and problem-solving skills in a collaborative environment.

Over the course of the semester, the students expressed a large number of metacognitive comments in their problemset reflections. Statistical analysis of our research shows a significant increase in the number of metacognitive comments over time. In the literature, Sandi-Urena, Cooper, and Gatlin found that well-established cooperative problembased chemistry laboratories improved graduate assistants' metacognition [49]. Similarly, Yuruk, Beeth, and Anderson showed that teaching activities focusing on metacognitive knowledge and processes improved students' conceptual understanding of Newtonian physics [14]. Our finding is in line with earlier studies showing that metacognition can be taught and shows that requiring students to monitor and evaluate the reasonableness of their solutions is an effective way to improve metacognition [14,49-51]. We find the effect size for the difference in the number of metacognitive comments between the beginning and the end of the semester is 0.4. This large effect size indicates that students' metacognitive skills improve significantly over the course of the semester.

The highest number of comments in the knowledge of cognition category may be related to the nature of the reflection form. In other words, when we ask "Describe what you learned from working on this problem set before coming to class and reviewing it in class," the students reflect about themselves as learners when they respond to this question. While we did not find a significant increase in the regulation of cognition category over time, the ability to evaluate the final result increased over the semester which means that more students were realizing the importance of checking the reasonableness of their final answers. Thus, these data suggest that this form facilitates the reflection of the students regarding their knowledge as learners but does not encourage the reflection about their regulation of skills acquisition.

Metacognition involves in-depth thinking during which the cognitive processes involved in learning are actively controlled. In our study, we found that the difference in students' evaluation of their own level of understanding and performance decreased. This indicated that students' metacognitive skills developed. This finding supports Cooper, Sandi-Urena, and Stevens' findings that students' ability to measure the difficulty of problems in chemistry increased with metacognitive activities [51].

From the students' comments in the $p$-set reflections, we can also conclude that the team phase contributes to the development of cognitive, metacognitive, and motivational skills. This finding agrees with earlier work reporting on the improvement of students' problem-solving ability and metacognitive skills as a result of collaborative work [35-38]. Specifically, because metacognitive experiences are related with affective elements [52], the collaborative work enriches social processes involved in metacognition and increases their motivation [5].

We do not observe a significant difference in the number of metacognitive comments for females and males. For both females and males, we observe a statistically significant decrease in the difference between students' actual RAA scores and the self-rating of their overall understanding (ORU). Overall, both male and female students develop a more realistic assessment of their own understanding over the course of the semester. However, females self-rated their understanding less than males despite there being no significant difference between them. This difference could be related to the fact that, when we measure student self-efficacy at the beginning of the semester, female students have significantly lower physics selfefficacy than male students [53].

During the semester, students treat the problem set as an open-book take-home exam, even though they are not evaluated on the correctness of their answers. Because their work is assessed on individual effort and correct evaluation of their own level of understanding, the problem sets become an opportunity to learn and develop strategic thinking. The four-step problem-solving procedure helps students develop good problem-solving practices that include articulating expectations for the solution to a 
problem before diving into the details, breaking down longer problems into smaller, more manageable pieces, verifying the solution by justifying the reasonableness of the answer, checking the symmetry of their solution, evaluating limiting or special cases, relating the solution to situations with known solutions, checking units, dimensional analysis, and/or checking the order of magnitude of the answer. As Flavell [17] suggested, these kinds of metacognitive experiences may improve students' metacognition. For this reason, this design helps students focus on the ways they process information.

Through the students' comments we find evidence that self-questioning and the act of discussing the thought process encourages students to examine and develop their metacognitive skills. The students' comments during the reflection part of the $p$ sets provide evidence that the team discussion also helps improve metacognitive skills. More importantly, students' expressions of metacognitive thinking improve over the course of the term, highlighting the importance of all the procedures in their implementation, namely, the four-step problem-solving strategy, discussion in the class, and the scoring format (based on the reflection and effort).

\section{CONCLUSION}

In this paper we present a novel homework strategy designed to help students develop self-assessment, metacognition, and problem-solving skills in a collaborative environment. We have studied (i) improvement of students' metacognitive skills over the course of the semester and (ii) the relationship between students' rating of their own understanding and their performance in the course.

We find that this homework approach, implemented in a team-based learning environment, improves students' metacognitive skills over the course of the semester. We also show a significant decrease in the difference between students' rating of their own understanding and their performance in the course, which suggests that they improve in their ability to accurately assess their own level of conceptual understanding. These findings lead us to believe that the purposeful social interaction and the reflective prompting motivated by the individual and team phase of the homework implementation act as promoters of metacognitive development. Our research suggests that this homework design is a successful strategy to increase students' metacognition through prompting and collaboration, because it helps them become more reflective and aware of their own problem-solving process. The strategy presented in this paper better prepares students for future learning as they spontaneously adapt their knowledge to new situations. Because metacognition plays an important role in students' learning of physics [11,54], pedagogical approaches such as the one presented in this paper are a powerful resource to help instructors bring metacognition into science classrooms.

\section{ACKNOWLEDGMENTS}

The authors are pleased to acknowledge the help of Professor Cleci Werner da Rosa, from Universidade de Passo Fundo, Brazil, and Professor Şakir Erkoç, from Middle East Technical University for providing feedback. The authors also acknowledge financing of Fundação da Ciência e Tecnologia, of COMPETE 2020 program in FEDER component (European Union), through Project No. UID/FIS/04650/2013, Zonguldak Bülent Ecevit University, Turkish Academy of Sciences (TÜBAGEBIP/2017), and National Science Foundation (NSF DUE-1504664) for supports to this research. 


\section{APPENDIX A: SAMPLE REFLECTION FORM}

At the end of the team phase, students completed this self-evaluation/reflection and delivered this document to the teaching staff.

\section{Problem Set Reflection Name: _}

1. List any assistance you sought while creating my solutions and/or places you got "stuck":

$$
\text { I ised the lextbool for the last ku queptios. }
$$

2. Now mark up your solutions, using the following color scheme. Use red to identify any errors that reflect a lack of conceptual understanding (for Instance, a physics or mathematics concept you did not understand). Use blue to identify any errors that refiect procedural mistakes in executing the problem (for example, incorrect substitution. calculation error, etc.). Add a few words deseribing the mistake(s) you identifled.

3. Describe what you learned from creating this problem set or reviewing it in class. (Do you think you would be able to take the concepts you explored in this problem set and transfer those concepts in a whole new context? For example. would you be able to solve a.problem involving the same physics concepts, but of a form you have neyer seen before?t? Buth doin the p.blum set on my oum and falking atout i) mith my terimmates mene vsefil ficturities. Oon my own, I strigled thingh some of the probleins and

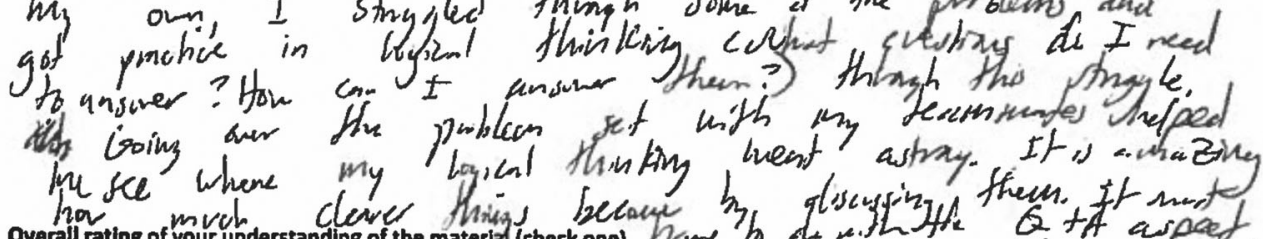

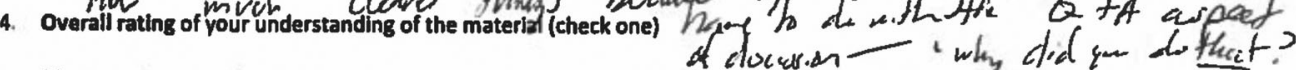

Geeen: good general understanding (How do you know? What did you do to ensure you understood the material?) Vellowish ilveen

Yellow: some barriers in understanding (What are those barriers? What efforts did you take to overcome such conceptual barriers?) We will provide advice on how to overcome the barriers you identlfied.

Red: substantial barriers in understanding (Did you seek out any of the course resources to hone-in on those challenges? What are some strategles you will implement to better learn those concepts and overcome such conceptual barriers?) We will work elosely with you to help address the barriers you identify.

Please elaborate here on potential barriers and your plans to address these:

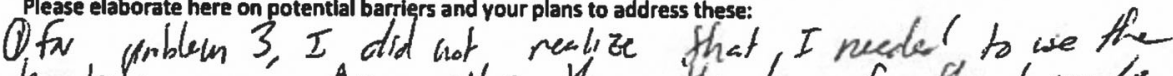

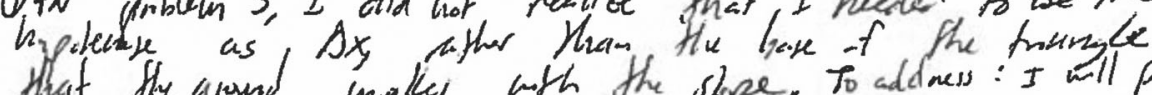

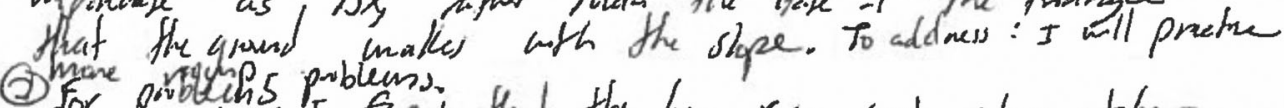

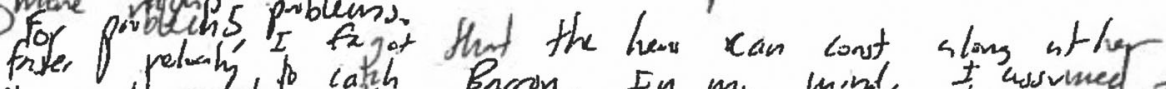

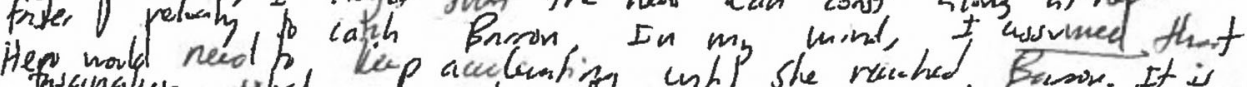

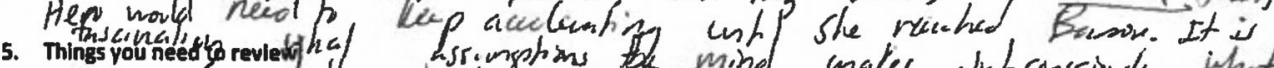

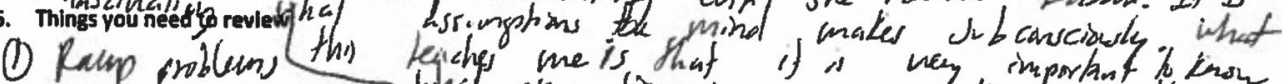

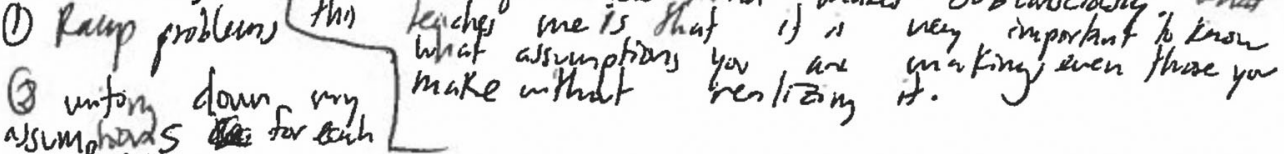
(n) bum. 


\section{APPENDIX B: $p$-SETS RUBRIC}

The $p$ set is evaluated based on effort and reflection score.

\section{Scoring}

Your problem set will be evaluated in two domains, using the standard 0-3 scale.

Effort All steps of the four-step problem-solving procedure written in blue or black ink show convincing effort on

$3=$ all problems

$2=$ more than $75 \%$ of the problems

$1=$ more than $50 \%$ of the problems

$0=50 \%$ or fewer of the problems

Reflection You clearly identify and explain (in red ink) any conceptual errors you made (or encountered) when you worked on the problem alone, as well as any mechanical errors you made on

$3=$ all problems and you submit a complete reflection sheet

$2=$ more than $75 \%$ and you submit a complete reflection sheet

$1=$ more than $50 \%$ and you submit a complete reflection sheet

$0=50 \%$ or fewer of the problems OR you do not submit a complete reflection sheet

These two scores are combined into an individual score as follows:

33 in Effort and Reflection

22 in both domains or one 2 and one 3

11 in either domain

00 in either domain

Your individual score will be combined with a team score that is obtained by averaging the individual scores of all team members and rounding the result to the nearest integer. For example, if your team scored $3,2,1,2$, and 1 , the team score is $(3+2+1+2+1) / 5=9 / 5$, which rounds to 2 . The team member with an individual score of 1 , obtains a problem-set score of 1.5 ; the team member with an individual score of 3, obtains a problem-set score of 2.5.

If you miss the team phase, but hand in your individual work before the due date, we will evaluate that work on Effort only. Your individual score will not be taken into account in the team score and the team score will not factor into your problem set score. Instead, your individual score will be divided by two. Any work submitted after the deadline will not be accepted. If extenuating circumstances exist, we will ask you to provide documentation directly issued by the University, and we will try to work out an agreeable solution with you.

[1] J. R. Baird, Improving learning through enhanced metacognition: A classroom study, Eur. J. Sci. Educ. 8, 263 (1986).

[2] P. R. Pintrich, The role of metacognitive knowledge in learning, teaching, and assessing, Theory Into Practice 41, (2002).

[3] P. Georghiades, From the general to the situated: Three decades of metacognition, Int. J. Sci. Educ. 26, 365 (2004).

[4] D. Rickey and A. M. Stacy, The role of metacognition in learning chemistry, J. Chem. Educ. 77, 915 (2000).

[5] C. Zepeda, J. Richey, P. Ronevich, and T. Nokes-Malach, Direct instruction of metacognition benefits adolescent science learning, transfer, and motivation: An in vivo study, J. Educ. Psychol. 107, 954 (2015).

[6] J. Greene and R. Azevedo, A macro-level analysis of SRL processes and their relations to the acquisition of a sophisticated mental model of a complex system, Contemp. Educ. Psychol. 34, 18 (2009).

[7] R. Fisher, Thinking about thinking: Developing metacognition in children, Early child development and care : ECDC 141, 1 (1998).
[8] J. L. Nietfeld and G. Shraw, The effect of knowledge and strategy explanation on monitoring accuracy, J. Educ. Res. 95, 131 (2002).

[9] K. W. Thiede, M. C. Anderson, and D Therriault, Accuracy of metacognitive monitoring affects learning of texts, J. Educ. Psychol. 95, 66 (2003).

[10] A. H. Schoenfeld, Explicit heuristic training as a variable in problem-solving performance, J. Res. Math. Educ. 10, 173 (1979).

[11] P. Georghiades, Research Report-Making pupils' conceptions of electricity more durable by means of situated metacognition, Int. J. Sci. Educ. 26, 85 (2004).

[12] A. J. Neto and M. O. Valente, Problem solving in physics: Towards a synergetic metacognitively developed approach, Paper presented at the annual meeting of the National Association for Research in Science Teaching, 1997, https:/files.eric.ed.gov/fulltext/ED405217.pdf.

[13] P. Rozencwajg, Metacognitive factors in scientific problemsolving strategies, Eur. J. Psychol. Educ. 18, 281 (2003).

[14] N. Yuruk, M. E. Beeth, and C. Andersen, Analyzing the effect of metaconceptual teaching practices on students' 
understanding of force and motion concepts, Res. Sci. Educ. 39, 449 (2009).

[15] A. Zohar and S. Barzilai, A review of research on metacognition in science education: Current and future directions, Stud. Sci. Educ. 49, 121 (2013).

[16] G. Taasoobshirazi, M. Bailey, and J. Farley, Physics metacognition inventory part II: Confirmatory factor analysis and Rasch analysis, Int. J. Sci. Educ. 37, 2769 (2015).

[17] J. Flavell, Metacognition and Cognitive monitoring: A new area of cognitive-development inquiry, Am. Psychol. 34, 906 (1979).

[18] G. Schraw and R. S. Dennison, Assessing metacognitive awareness, Contemp. Educ. Psychol. 19, 460 (1994).

[19] G. Schraw and D. Moshman, Metacognitive theories, Educ. Psychol. Rev. 7, 351 (1995).

[20] R. Mayer, Cognitive, metacognitive, and motivational aspects of problem solving, Instr. Sci. 26, 49 (1998).

[21] E. F. Redish, R. E. Scherr, and J. Tuminaro, Reverse engineering the solution of a "simple" physics problem: Why learning physics is harder than it looks, Phys. Teach. 44, 293 (2006).

[22] A. B. Lewis, Training students to represent arithmetic word problems, J. Educ. Psychol. 81, 521 (1989).

[23] G. Polya, How to Solve It (Princeton University Press, Princeton, NJ, 1945).

[24] R. Mayer, Thinking, Problem Solving, Cognition, 2nd ed. (Freeman, New York, 1992).

[25] R. Fogarty, How to Teach for Metacognition (IRI/Skylight Publishing, Palatine, 1994).

[26] R. E. Mayer, Educational Psychology: A Cognitive Approach (Harper, New York, 1987).

[27] M. Pressley, Cognitive Strategy Instruction (Brookline Books Cambridge, MA, 1990).

[28] P. R. Pintrich and E. V. De Groot, Motivation and selfregulated learning components of classroom academic performance, J. Educ. Psychol. 82, 33 (1990).

[29] W. Adams and C. Wieman, Analyzing the many skills involved in solving complex physics problems, Am. J. Phys. 83, 459 (2015).

[30] E. Kim and S.-J. Pak, Students do not overcome conceptual difficulties after solving 1000 traditional problems, Am. J. Phys. 70, 759 (2002).

[31] B. Sherin, Common sense clarified: The role of intuitive knowledge in physics problem solving, J. Res. Sci. Teach. 43, 535 (2006).

[32] S. C. Nurrenbern and M. Pickering, Concept learning versus problem solving: Is there a difference, J. Chem. Educ. 64, 508 (1987).

[33] B. A. Sawrey, Concept learning versus problem solving: Revisited, J. Chem. Educ. 67, 253 (1990).

[34] M. S. Cracolice, J. C. Deming, and B. Ehlert, Concept learning versus problem solving: A cognitive difference, J. Chem. Educ. 85, 873 (2008).

[35] P. Heller, R. Keith, and S. Anderson, Teaching problem solving through cooperative grouping. Part 1: Group versus individual problem solving, Am. J. Phys. 60, 627 (1992).
[36] P. Heller and M. Hollabaugh, Teaching problem solving through cooperative grouping. Part 2: Designing problems and structuring groups, Am. J. Phys. 60, 637 (1992).

[37] S. Sandi-Urena, M. M. Cooper, and R. H. Stevens. Enhancement of metacognition use and awareness by means of a collaborative intervention, Int. J. Sci. Educ. 33, 323 (2011).

[38] M. M. Cooper, C. T. Cox, M. Nammouz, and E. Case, An assessment of the effect of collaborative groups on students' problem-solving strategies and abilities, J. Chem. Educ. 85, 866 (2008).

[39] C. Singh, When physical intuition fails, Am. J. Phys. 70, 1103 (2002).

[40] E. Mazur, Peer Instruction: A User's Manual (Prentice Hall, Inc., Englewood Cliffs, NJ, 1997).

[41] K. Miller, S. Zyto, D. Karger, J. Yoo, and E. Mazur, Analysis of student engagement in an online annotation system in the context of a flipped introductory physics class, Phys. Rev. Phys. Educ. Res. 12, 020143 (2016).

[42] L. C. McDermott and P. S. J. Shaffer, Tutorials in Introductory Physics (Pearson, Upper Saddle River, NJ, 2001).

[43] G. Taasoobshirazi and J. Farley, Construct validation on the physics metacognition inventory, Int. J. Sci. Educ. 35, 447 (2013).

[44] M. D. LeCompte and J. P. Goetz, Problems of reliability and validity in ethnographic research, Rev. Educ. Res. 52, 31 (1982).

[45] M. B. Miles and A. M. Huberman, Qualitative Data Analysis (Sage Publications, Newbury Park, CA, 1984).

[46] L. Hsu, E. Brewe, T. M. Foster, and K. A. Harper, Resource letter RPS-1: Research in problem solving, Am. J. Phys. 72, 1147 (2004).

[47] J. L. Docktor and J. P. Mestre, Synthesis of disciplinebased education research in physics, Phys. Rev. ST Phys. Educ. Res. 10, 020119 (2014).

[48] F. Reif and J. I. Heller, Knowledge structure and problem solving in physics, Educ. Psychol. 17, 102 (1982).

[49] S. Sandi-Urena, M. M. Cooper, and T. A. Gatlin, Graduate teaching assistants' epistemological and metacognitive development, Chem. Educ. Res. Pract. 12, 92 (2011).

[50] C. Singh, When physical intuition fails, Am. J. Phys. 70, 1103 (2002).

[51] M. M. Cooper, S. Sandi-Urena, and R. Stevens, Reliable multi method assessment of metacognition use in chemistry problem solving, Chem. Educ. Res. Pract. 9, 18 (2008).

[52] A. Efklides, Metacognition and affect: What can metacognitive experiences tell us about the learning process?, Educ. Res. Rev. 1, 3 (2006).

[53] T. Espinosa, K. Miller, I. Araujo, and E. Mazur, Reducing the gender gap in students' physics self-efficacy in a teamand project-based introductory physics class, Phys. Rev. Phys. Educ. Res. (to be published).

[54] N. Didiş Körhasan, A. Eryılmaz, and Ş. Erkoç, The role of metacognition in students' mental models of the quantization, Sci. Educ. Int. 29, 183 (2018); https://files.eric.ed .gov/fulltext/EJ1190550.pdf. 